\title{
Análise de Conteúdo Multimídia para Radiodifusão Digital Operando na Faixa de Ondas Curtas
}

\author{
Hebert Santos, Amanda A. Menezes, Gilvandson C. Cavalcante, Sidnei Baumann, Flávio F. Lima
}

\begin{abstract}
This paper intends to evaluate the main tools of multimedia services used in currently media, identifying those that are best suited to digital broadcasting service in the range of shortwave, taking into account the best technical characteristics for the production of content to be transmitted in narrowband technology.
\end{abstract}

Index Terms - Shortwave, Digital Radio, Digital Radio Mondiale, Multimedia.

\section{INTRODUÇÃO}

$\mathrm{C}$ OM o surgimento de novas tecnologias digitais, incluindo $C_{a s}$ tecnologias desenvolvidas para o setor de radiodifusão, e a convergência de conteúdo entre as mídias, o número de possibilidades de prestação de serviço com uso dessas mídias aumenta consideravelmente. A digitalização da radiodifusão sonora permite aos usuários receberem, além do áudio de melhor qualidade, dados com programação multimídia. Nesse cenário, há um interesse crescente no desenvolvimento de conteúdos e de novas metodologias de inclusão social, utilizando o rádio digital.

Assim, a radiodifusão em ondas curtas - OC surge com grande destaque, devido às características de propagação nessa faixa de frequência, que permitem áreas de coberturas nacionais e transcontinentais por meio de uma única emissora.

Apesar dos sinais propagados nessa faixa estarem mais propícios aos ruídos e aos desvanecimentos que os sinais em frequências superiores, diferentemente do sistema analógico que não é capaz de tratar adequadamente essas interferências, o sistema digital permite a correção de erros na recepção por meio de códigos corretores de erros e técnicas de modulação.

Por outro lado, a largura de banda disponível para as emissoras de radiodifusão nessa faixa de frequência não é suficiente para proporcionar as altas taxas de transmissão de dados que são praticadas em outros meios de comunicação, tais como na internet em banda larga, o que torna mais cuidadoso o desenvolvimento de conteúdo para esse tipo de tecnologia.

Artigo submetido no dia 29 de maio de 2015.

H. Santos, engenheiro do Ministério das Comunicações, Goiânia-GO, Brasil, email: hebert.santos@comunicacoes.gov.br.

F.F. Lima, professor da Faculdade Anhanguera em Brasília, Unidade Facnet, Brasil, email: flavio.lima@anhanguera.com.
Portanto, esse artigo visa avaliar a aplicação de algumas ferramentas utilizadas nos serviços multimídia, de forma a identificar, dentre elas, aquelas que melhor atendem à produção de conteúdo a ser transmitido em tecnologia de banda estreita. Para tanto, o artigo está estruturado em seis seções. Na primeira, é delineada a fundamentação do trabalho. Na segunda, é apresentado um overview do sistema DRM (Digital Radio Mondiale), destacando as característica técnicas, os serviços adicionais contemplados além do áudio, e a capacidade de transmissão em bps (bit por segundo) do sistema em função da escolha do modo de transmissão (robustez do sinal diante das características do canal de transmissão).

$\mathrm{Na}$ seção seguinte, por meio de algumas ferramentas, é realizado um conjunto de análises de conteúdo multimídia, identificando os formatos que mais se adequam ao sistema. Na seção IV, é apresentado o desenvolvimento de uma plataforma para transmissão e recepção do sinal na faixa de ondas curtas, utilizada na avaliação dos conteúdos transmitidos na seção V. Por fim, na última seção, são delineadas as conclusões e as considerações finais dos estudos realizados.

\section{SISTEMA DRM}

O Sistema DRM, foi criado em Guangzhou - China, em 1998, inicialmente com o objetivo de digitalização das bandas de radiodifusão $\mathrm{AM}$ até $30 \mathrm{MHz}$ (ondas longas, médias e curtas). A especificação do sistema DRM para a transmissão abaixo de $30 \mathrm{MHz}$ é denominado de DRM30, e foi publicada pela primeira vez pelo ETSI (European Telecommunications Standards Institute) em 2001 [1], seguido de uma Recomendação ITU (International Telecommunication Union) definindo a utilização do sistema de radiodifusão sonora digital a nível internacional [2].

\section{A. Características Técnicas}

O sistema DRM30 foi desenvolvido de forma que alguns parâmetros técnicos possam ser ajustados, tais como: tipos de modulações, modos de transmissões OFDM (Orthogonal

G. C. Cavalcante, mestrando da Universidade de Brasília, Brasília-DF, Brasil, email: gilvandson.cavalcante@gmail.com.br.

A. A. Menezes, mestranda da Universidad Nihon Gakko, Ciudad Del Lest, Paraguai-PY, email: amanda@,facnet.com.br.

S. Baumann, professor da Universidad Nihon Gakko, Ciudad Del Lest, Paraguai-PY, email: sidnei@qualityeletro.com.br. 
Frequency Division Modulation), taxas de codificação de canal e variações de interleaving. Assim, o sistema pode ser configurado de maneira a adequar a sua transmissão às necessidades das emissoras, que podem optar por uma maior taxa de dados úteis ou uma maior robustez do sinal irradiado frente às imperfeições do canal de transmissão, tais como: efeitos dos ruídos, interferências, multipercursos e efeito Doppler.

Além dos parâmetros citados, é possível escolher uma dentre seis larguras espectrais para o sinal digital DRM30; são elas: 4,5 kHz, $5 \mathrm{kHz}, 9 \mathrm{kHz}, 10 \mathrm{kHz}, 18 \mathrm{kHz}$ ou $20 \mathrm{kHz}$, o que permite uma transmissão full digital ou simulcast. Ademais, o sistema DRM30 é identificado de acordo com os modos de transmissão OFDM representados por meio de quatro letras, A, B, C e D, e classificados em função da duração dos símbolos OFDM e da duração do intervalo de guarda OFDM conforme ilustram a Tabela I e Tabela II [3].

TABELA I

PARÂMETROS OFDM DOS QUATRO MODOS DE ROBUSTEZ DO DRM30

\begin{tabular}{ccccc}
\hline \multirow{2}{*}{ Parâmetro } & \multicolumn{4}{c}{ Modo de Robustez } \\
& $\mathrm{A}$ & $\mathrm{B}$ & $\mathrm{C}$ & $\mathrm{D}$ \\
\hline $\begin{array}{c}\text { Espaçamento entre portadoras } \\
(\Delta \mathrm{fp})[\mathrm{Hz}]\end{array}$ & 41,667 & 46,875 & 68,182 & 107,143 \\
\hline $\begin{array}{c}\text { Duração da parte útil do símbolo } \\
(\mathrm{Tu}=1 / \Delta \mathrm{fp})[\mathrm{ms}]\end{array}$ & 24 & 21,333 & 14,667 & 9,333 \\
\hline $\begin{array}{c}\text { Intervalo de guarda } \\
(\mathrm{Tg})[\mathrm{ms}]\end{array}$ & 2,667 & 5,333 & 5,333 & 7,333 \\
\hline $\begin{array}{c}\text { Duração do símbolo OFDM } \\
(\mathrm{Ts}=\mathrm{Tu}+\mathrm{Tg})[\mathrm{ms}]\end{array}$ & 26,667 & 26,667 & 20 & 16,667 \\
\hline \hline $\mathrm{Tg} / \mathrm{Tu}$ & $1 / 9$ & $1 / 4$ & $4 / 11$ & $11 / 14$ \\
\hline \hline
\end{tabular}

TABELA II

MODOS DE ROBUSTEZ DO SISTEMA DRM30

\begin{tabular}{|c|c|c|}
\hline $\begin{array}{l}\text { Modo de } \\
\text { Robustez }\end{array}$ & $\begin{array}{c}\text { Condições de Propagação } \\
\text { Típicas }\end{array}$ & Usos Típicos \\
\hline A & $\begin{array}{l}\text { Onda de superfície, com } \\
\text { pouco desvanecimento. }\end{array}$ & $\begin{array}{l}\text { Cobertura local ou regional } \\
\text { usando onda de superfície nas } \\
\text { faixas OL e OM. Cobertura } \\
\text { local usando onda espacial na } \\
\text { faixa OC } 26 \mathrm{MHz} \text {. }\end{array}$ \\
\hline B & $\begin{array}{l}\text { Canais seletivos no tempo e } \\
\text { na frequência, com maior } \\
\text { delay spread. }\end{array}$ & $\begin{array}{l}\text { Cobertura nacional } \\
\text { internacional usando onda } \\
\text { celeste nas faixas OM e OC. }\end{array}$ \\
\hline $\mathrm{C}$ & $\begin{array}{l}\text { Idem modo B, mas com } \\
\text { elevado Doppler spread. }\end{array}$ & $\begin{array}{l}\text { Cobertura internacional usando } \\
\text { onda celeste na faixa OC. }\end{array}$ \\
\hline D & $\begin{array}{l}\text { Idem modo B, mas com } \\
\text { severos delay spread e } \\
\text { Doppler spread. }\end{array}$ & $\begin{array}{l}\text { Onda celeste requerendo } \\
\text { robustez altíssima, } \\
\text { particularmente onda celeste } \\
\text { com incidência quase vertical } \\
\text { para cobertura nacional na faixa } \\
\text { OT. }\end{array}$ \\
\hline
\end{tabular}

Portanto, observa-se pela Tabela I e pela Tabela II que a capacidade de transmissão de dados úteis está diretamente correlacionada com a escolha do modo de transmissão, sendo maior a taxa quanto menor a robustez do sistema. Assim, a escolha da qualidade do áudio e da taxa de bits reservada para transmissão de dados fica a critério do radiodifusor, em função da sua necessidade.

A Figura 1 apresenta de forma simplificada a configuração de uma estação transmissora no sistema DRM30. O sinal
DRM30 gerado por um servidor de conteúdo e um modulador, este último é conectado ao transmissor. O servidor de conteúdo é o equipamento onde o áudio é codificado, os parâmetros de transmissão são configurados e os demais dados multimídias são inseridos. O modulador gera os sinais que são enviados ao transmissor gerando o sinal DRM30. Nesta configuração o sinal AM e o sinal DRM30 estão em canais adjacentes, e o sinal na saída do transmissor AM constitui o sinal Simulcast ou híbrido.

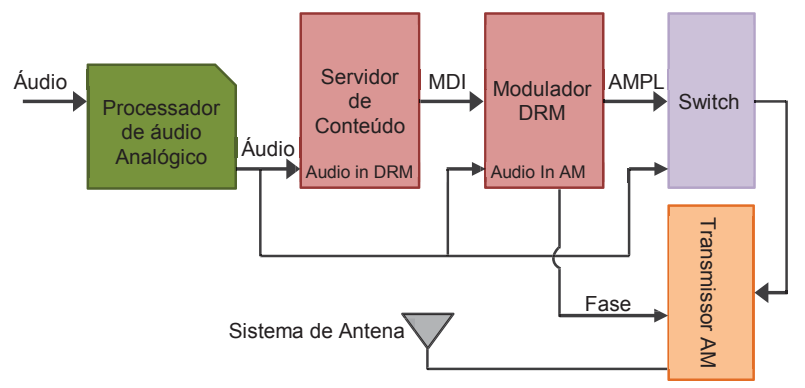

Fig. 1. Diagrama de bloco DRM30 transmissão simulcast.

\section{1) Estrutura Lógica do Sistema}

A estrutura lógica do sistema DRM30 é dividida em três canais: o canal de acesso rápido ou FAC (Fast Access Channel), o canal de descrição de serviço ou SDC (Service Description Channel) e o canal de serviço principal ou MSC (Main Service Channel) [2],[3].

O canal MSC contém os serviços de áudio e dados e, por isso, detém a maior parte da capacidade de transmissão do sinal DRM30, podendo transportar até quatro serviços distintos, de áudio e/ou dados. As portadoras que transportam dados do MSC podem utilizar a modulação 16-QAM ou a 64QAM.

O SDC contém a descrição de como decodificar os serviços contidos no MSC. As portadoras que transportam os dados do SDC sempre usam uma modulação mais robusta (isto é, de menor ordem) do que aquela utilizada pelo MSC. Assim, o MSC e o SDC utilizam, respectivamente, 64-QAM e 16QAM ou 16-QAM e 4-QAM.

$\mathrm{O}$ canal de acesso rápido ou $\mathrm{FAC}$ transporta dados que informam ao receptor a largura espectral do sinal DRM30, as modulações usadas com o SDC e com o MSC, o comprimento do embaralhamento (interleaving), quantos serviços contém o MSC e o nome desses serviços. O receptor decodifica primeiro o FAC, para depois decodificar o SDC e o MSC. Como o FAC transporta os dados mais críticos do sistema, ele requer maior robustez, que é conseguida com o uso da modulação 4-QAM e de um código FEC mais robusto.

\section{2) Codificação de Áudio}

O sistema DRM30 oferece grande flexibilidade na codificação de fonte, permitindo a utilização de dois esquemas de codificação para áudio mono e estéreo, MPEG xHE-AAC (Extended High-Efficiency Advanced Audio Coding) e o MPEG-4 AAC (Advanced Audio Coding) que pode ser utilizado em conjunto com as ferramentas SBR 
(Spectral Band Replication) e PS (Parametric Stereo), conforme ilustra a Figura 2. Ambos os codificadores trabalham com qualquer taxa de bits onde a granularidade é de 20 bps.

Por exemplo, na faixa de ondas curtas o xHe-AAC precisa de uma taxa de $16 \mathrm{kbps}$ (quilobit por segundo) para áudio com qualidade estéreo, e o MPEG-4 AAC de uma taxa de $20 \mathrm{kbps}$ para áudio com qualidade mono sem uso das ferramentas SBR e PS.

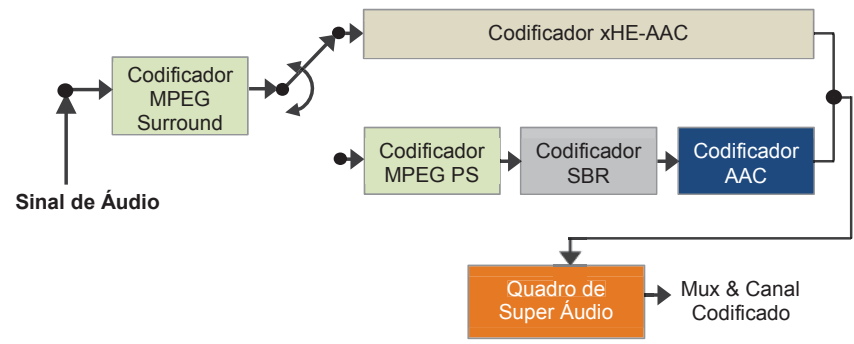

Fig. 2. Opções de codificação de áudio e voz no DRM30.

O codificador MPEG-4 AAC é usado para a codificação de áudio genérico, mono, estéreo ou surround. No sistema DRM30, as taxas de amostragem permitidas com o MPEG-4 AAC são de $12 \mathrm{kHz}$ ou $24 \mathrm{kHz}$. A princípio, o áudio codificado teria então uma largura de banda menor que $6 \mathrm{kHz}$ ou $12 \mathrm{kHz}$, respectivamente. No entanto, o sistema DRM30 permite o uso da técnica SBR, que é capaz de melhorar a percepção de um sinal de áudio realizando o truncamento das baixas frequências [4]. Ela usa, de forma dinâmica, o conteúdo espectral de informações de baixa frequência para criar uma imitação para as informações de alta frequência perdidas. Isto requer informações auxiliares do SBR que são aproximadamente de $2 \mathrm{kbps}$.

Neste caso, o codificador MPEG-4 AAC codifica um sinal de áudio de banda estreita - com largura de banda inferior a 6 ou $12 \mathrm{kHz}$ - e em paralelo o codificador SBR extrai e codifica apenas a forma (ou envoltória) do espectro de áudio original para frequências acima de 6 ou $12 \mathrm{kHz}$. Essas duas informações, a da saída do codificador MPEG-4 AAC e a da saída do codificador SBR, são transmitidas e usadas pelo decodificador para criar uma imitação das informações de alta frequência espectral perdidas, que são combinadas com as informações de baixa frequência espectral para produzir um sinal de áudio que se estende a $15 \mathrm{kHz}$ ou mais.

A combinação do codificador AAC com o esquema de SBR é chamado aacPlus ou HE AAC (High Efficiency AAC). O aacPlus é capaz de fornecer sinais de áudio estereofônico de alta qualidade, equivalente à qualidade oferecida por CDs, com taxas de bits em torno de $48 \mathrm{kbps}$, e sinais de áudio mono com qualidade próxima ao proporcionado pelas estações de FM com taxas de bits em torno de $20 \mathrm{kbps}$.

O sistema DRM30 permite também o uso de um sistema estéreo paramétrico, que usa uma técnica de síntese para decodificar o sinal de áudio para melhorar o mono AAC, dando a percepção de um sinal estéreo. Essa técnica também exige a transmissão de informações auxiliares de aproximadamente $2 \mathrm{kbps}$, e é extraído pelo codificador do sinal original de áudio estéreo. Portanto, para implementar a expansão de largura de banda, SBR, e o estéreo paramétrico é necessária uma taxa extra de bits de $4 \mathrm{kbps}$. No entanto, essas duas técnicas, quando combinadas com a codificação MPEG4 AAC, proporcionam uma excelente qualidade de áudio com uma taxa de bits total inferior a $20 \mathrm{kbps}$ [5].

\section{B. Serviços Adicionais}

Uma das principais vantagens na digitalização do rádio é a possibilidade de oferecer serviços adicionais além da melhoria na qualidade do áudio. Assim, atualmente o sistema DRM oferece um conjunto de serviços agregados à programação ou não, a saber [6].

\section{1) Alerta de Emergências}

Envio de sinais de alerta aos receptores provocando uma mudança automática de sintonia para os canais emergenciais. Os programas de Alertas Emergenciais contêm áudio e texto criando uma plataforma multilíngue para orientação e informação das populações em tempo real.

\section{2) Mensagem de Texto}

Acompanhamento da programação em áudio com textos curtos, tais como título da música ou artista (tela atualizada pelo radiodifusor), com suporte Unicode completo (scripts).

\section{3) Journaline}

Serviço de informação de texto Unicode (todos os Scripts), com pesquisa interativa de informações na tela do receptor, semelhante a uma navegação web.

\section{4) Geolocalização de Conteúdos}

Permite a oferta de serviços em zonas específicas.

\section{5) Slideshow}

Imagens e animação transmitidas em carrossel.

\section{6) Electronic Programme Guide (EPG)}

Inclui "What'supnow\&next"; o ouvinte pode visualizar a programação atual e futura da emissora, com opção para busca de conteúdos e memorização de programas.

\section{7) Transport Protocol Experts Group (TPEG) e Traffic Message Channel TMC}

Informações e mensagem de trânsito para sistemas móveis (automóveis).

\section{8) Diveemo}

Vídeo em pequena escala para serviços de informação e educação (em processo de homologação).

\section{Capacidade de Transmissão}

O sistema DRM30 permite transmitir vários tipos de serviço, no entanto, a possibilidade destes serviços serem oferecidos simultaneamente é restringida pela capacidade do canal. Essa limitação pode ser observada na Figura 3, com a taxa de dados (bits/s) em função do modo de transmissão e do 
nível de proteção, adotando uma largura de banda de $10 \mathrm{kHz}$.

Para cada modo de robustez, A, B, C ou D, existem dois esquemas de modulação para o canal MSC, 16-QAM ou 64QAM, os quais podem ser utilizados em combinação com o codificador de canal. Cada nível de proteção é caracterizado por um parâmetro específico definido para os codificadores convolucionais, resultando em uma determinada taxa média de código para o multinível global do processo de codificação no modulador.

Assim, à medida que a taxa de nível de proteção vai se alterando dentro do mesmo modo de robustez, a taxa de dados em bps úteis também se altera, caracterizando a capacidade do canal.

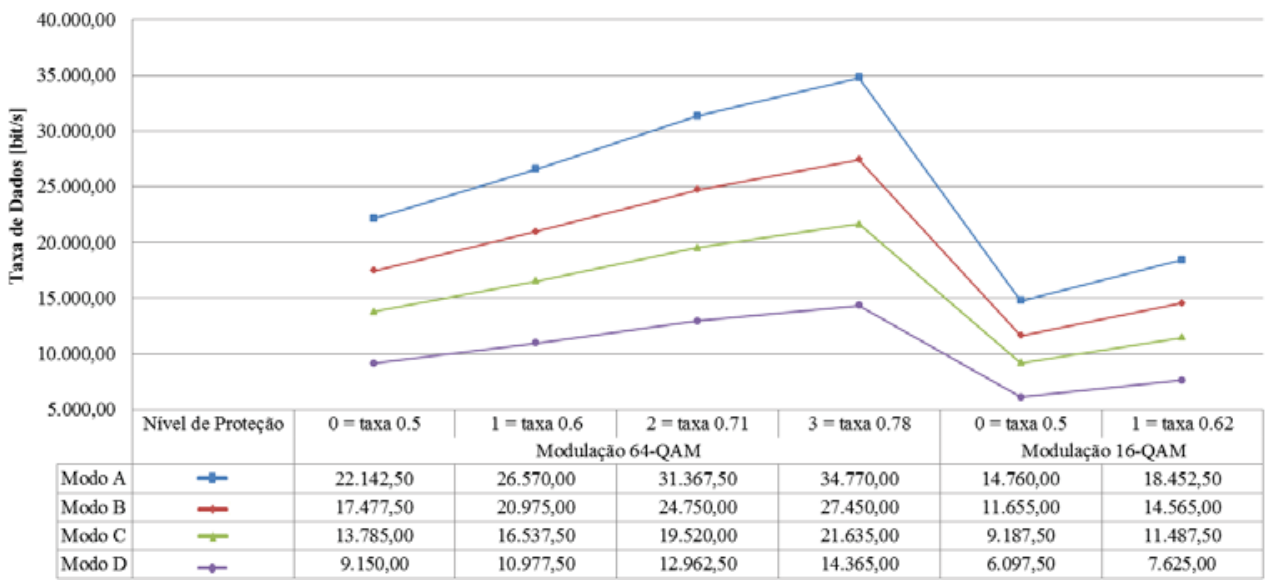

Fig. 3. Taxa de dados em função da modulação e nível de proteção.

\section{ANÁLISE DE CONTEÚdOS MULTIMÍDIAS}

Diante de um sistema de largura de banda estreita de 10 $\mathrm{kHz}$, quanto menos bits forem atribuídos para proteção do sinal, maior será a capacidade de transmissão de dados úteis do sistema. Por outro lado, ao atribuir uma baixa proteção, o mesmo poderá não conseguir desempenhar sua tarefa principal, que é a decodificação do conteúdo recebido, deixando o sistema vulnerável aos ecos, e consequentemente a erros de operação. Diante desse cenário, verifica-se a importância de se estabelecer critérios para a elaboração dos conteúdos multimídias que irão trafegar no sistema, possibilitando a maximização e a eficiência dos recursos disponíveis.

\section{A. Arquivos de Imagens}

Uma das principais características dos sistemas multimídia consiste na utilização de imagens para compor o conteúdo a ser transmitido. Assim é extremamente importante analisar quais formatos de dados possuem melhor desempenho na transmissão do conteúdo e que são factíveis de codificação e decodificação pelo sistema DRM30. Para essa avaliação, foi utilizado o banco de imagens TID2008 [7], por ser gratuito e de alta qualidade.

O banco de dados TID2008 conta com um total de 25 imagens de referências no formato bitmap (BMP), e 1700 imagens degradadas por 17 diferentes meios de distorção, provenientes das imagens de referências. Ele reflete uma boa diversidade de conteúdo. As imagens incluem rostos, pessoas, animais, cenas naturais e objetos.

Três imagens de referência foram selecionadas pela sua riqueza de detalhes, conforme ilustra a Figura 4, proporcionando assim uma análise mais evidente dos tipos de conversão aplicados. As imagens originalmente possuíam dimensões $512 \times 384$ pixels. No entanto, os receptores padrões de rádio digital possuem telas de tamanho de $320 \times$ 240 pixels. Assim, para transmissão das imagens, as mesmas foram reduzidas para $320 \times 240$ pixels, possibilitando assim uma redução para aproximadamente $39 \%$ de seu tamanho, em se tratando de ocupação de armazenamento e transmissão, passando de $577 \mathrm{kB}$ (quilo Byte) para $226 \mathrm{kB}$ cada uma.

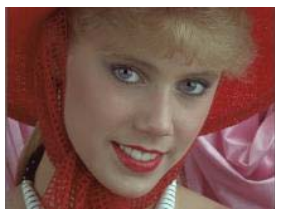

(a) Imagem I01

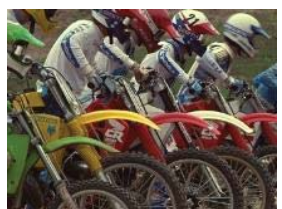

(b) Imagem I02

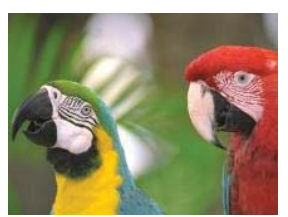

(c) Imagem I03 Fig. 4. Imagens escolhidas.

Após o redimensionamento das imagens BMP para $320 \times$ 240 pixels, cada imagem de referência foi convertida nos padrões JPEG (Joint Photographics Experts Group), PNG, (Portable Network Graphics) GIF (Graphics Interchange Format), Webp com fator de compressão de 75 e SVG (Scalable Vector Graphics), conforme ilustra a Figura 5.

Observa-se que os três arquivos de imagens de referência apesar de possuírem o mesmo tamanho no formato Bitmap, ao serem convertidos para um outro formato, por exemplo, o JPEG, apresentam tamanhos diferentes. Esta característica se deve ao fato de como cada algoritmo de conversão de imagens trata as riquezas de detalhes. Observando as imagens e comparando-as, pode-se verificar que a imagem I02 possui maior quantidade de detalhes e cores, resultado assim em um arquivo final JPEG maior que os demais. 


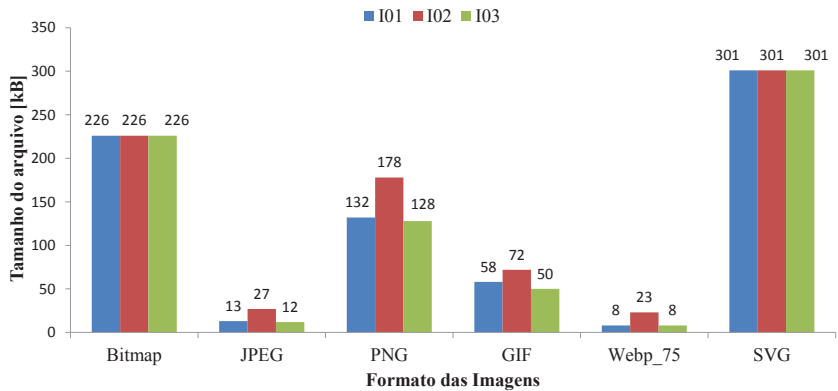

Fig. 5. Comparação entre os tipos de padrões de imagens.

Nos processos de compressão utilizados neste trabalho, todos apresentaram perdas de informação que resultam na degradação da imagem convertida. No entanto, estas perdas podem afetar a qualidade visual da imagem ou não. Para se identificar o grau dessa degradação, utiliza-se a comparação por meio da Razão Sinal Ruído de Pico (PSNR), onde o sinal é a imagem original e o ruído o erro introduzido pela compressão [8]. Observando a Figura 5, tem-se que os dois padrões de imagens que apresentaram melhor comportamento no que se refere à economia de espaço em disco foram o JPEG e o Webp. Assim a análise da PSNR restringiu-se a estes dois padrões.

Para o cálculo da PSNR do padrão JPEG, foi implementado no software MatLab um código onde as três imagens em JPEG, uma de cada vez, foram submetidas a uma variação de seu Fator de Compressão (FC), de 0 a 100\% com intervalos de $5 \%$, sendo que o fator $0 \%$ corresponde a uma máxima compressão e o fator $100 \%$ corresponde a nenhuma compressão.

A Figura 6 ilustra o valor de PSNR em função da quantidade de bit por pixel. Uma imagem com valor de PSNR maior que 41 é considerada adequada para utilização, ou seja, a degradação não é significativamente perceptível ao usuário [9]. As Figuras 7, 8 e 9 ilustram a qualidade das imagens em função da variação do Fator de Compressão (FC), da PSNR, e da quantidade de Bits por Pixel (B/P).

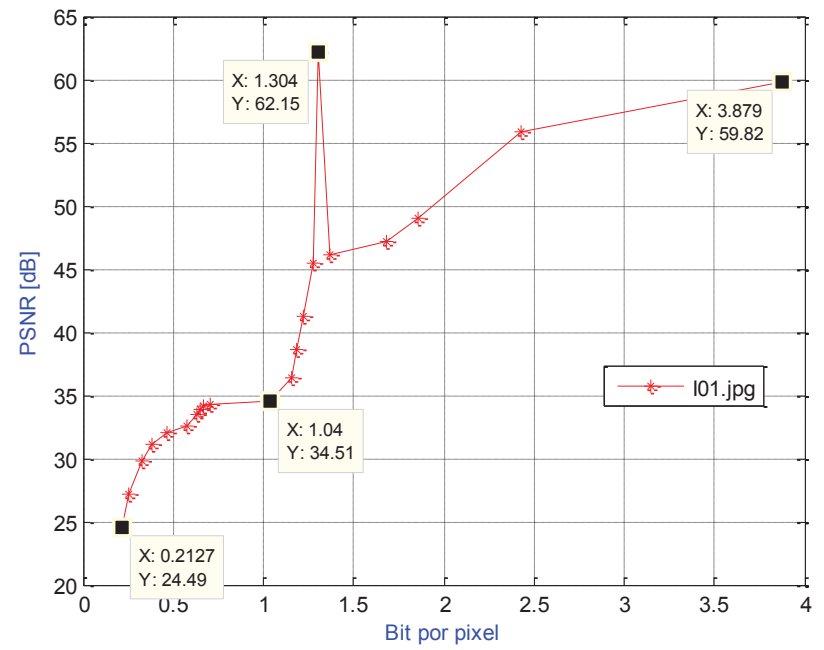

Fig. 6. PSNR em função de Bit por pixel da Imagem I01.

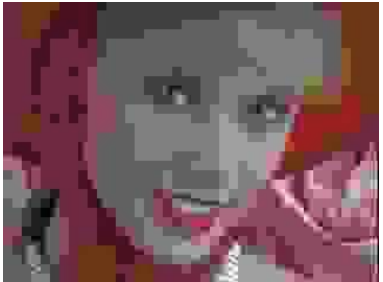

(a) $\mathrm{FC}=0 \%$; PSNR $=24,49$;

$\mathrm{B} / \mathrm{P}=0,2127$

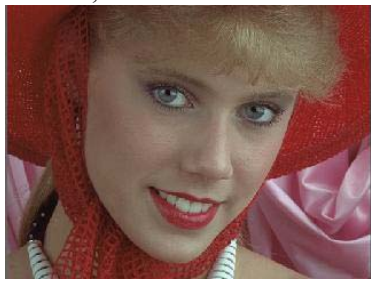

(c) $\mathrm{FC}=75 \%$; PSNR $=62,15$; $\mathrm{B} / \mathrm{P}=1,304$

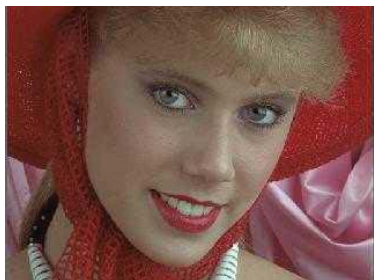

(b) $\mathrm{FC}=50 \%$; $\mathrm{PSNR}=34,51$; $\mathrm{B} / \mathrm{P}=1,040$

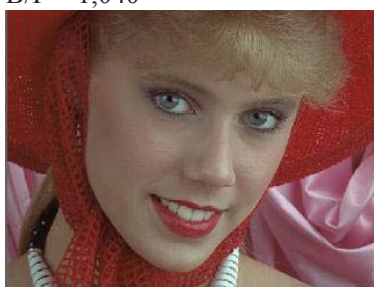

(d) $\mathrm{FC}=100 \% ; \quad \mathrm{PSNR}=59,82$; $\mathrm{B} / \mathrm{P}=3,879$

Fig. 7. Representação da Imagem I01 com variação do FC.

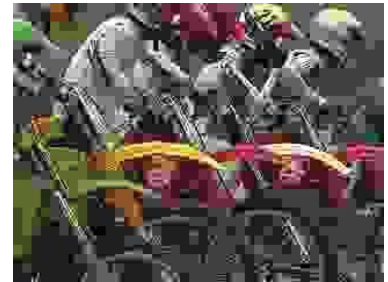

(a) $\mathrm{FC}=0 \% ;$ PSNR $=18,29$;

$\mathrm{B} / \mathrm{P}=0,3069$

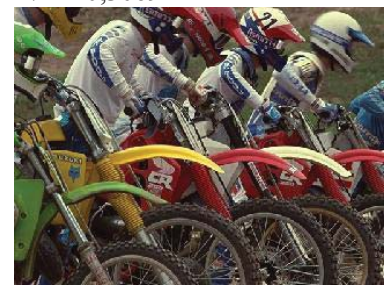

(c) $\mathrm{FC}=75 \% ; \mathrm{PSNR}=54,44$; $\mathrm{B} / \mathrm{P}=2,858$

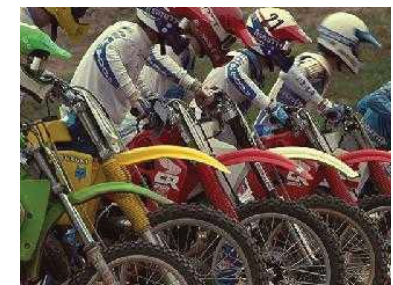

(b) $\mathrm{FC}=50 \%$; PSNR $=25,79$; $\mathrm{B} / \mathrm{P}=2,193$

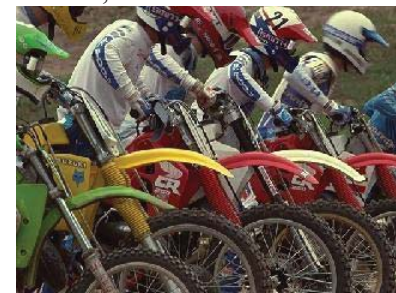

(d) $\mathrm{FC}=100 \%$; PSNR $=57,49$; $\mathrm{B} / \mathrm{P}=8,107$

Fig. 8. Representação da Imagem I02 com variação do FC.
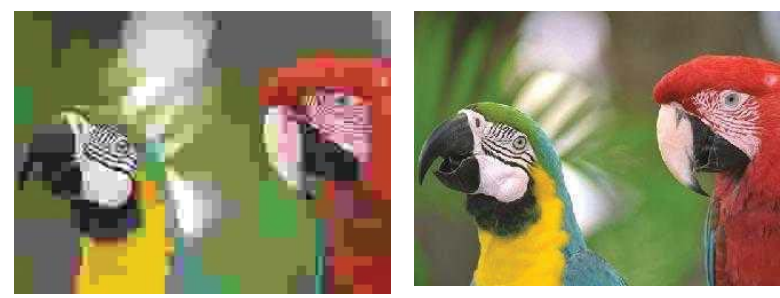

(a) $\mathrm{FC}=0 \%$; PSNR $=23,48$;

$\mathrm{B} / \mathrm{P}=0,2303$

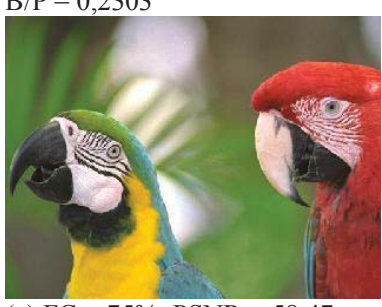

(c) $\mathrm{FC}=75 \%$; $\mathrm{PSNR}=58,47$; $\mathrm{B} / \mathrm{P}=1,278$

(b) $\mathrm{FC}=50 \%$; PSNR $=33,05$; $\mathrm{B} / \mathrm{P}=0,9935$

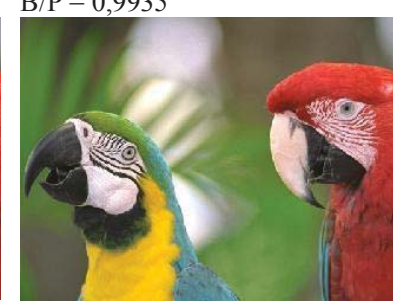

(d) $\mathrm{FC}=100 \%$; PSNR $=59,11$; $\mathrm{B} / \mathrm{P}=4,083$

Fig. 9. Representação da Imagem I03 com variação do FC.

Portanto, quando se observa a degradação da imagem devido à sua compressão, pode-se traçar um paralelo entre a 
PSNR, o fator de compressão e a quantidade de bits por pixel. À medida que se comprime a imagem, a quantidade de bits por pixel diminui e o fator PSNR torna-se menor. Desta forma, ao se comparar um sinal antes e depois de um processo de degradação, deve-se verificar o valor do PSNR obtido. Se for um alto valor, significa que a imagem que foi submetida ao processo de compressão tem uma melhor qualidade. Verificada esta relação, uma comparação válida neste caso é o comportamento do arquivo em relação ao seu tamanho quando se varia o fator de compressão, tendo como resultado o PSNR.

Esse comparativo pode ser observado para cada uma das imagens, nos formatos JPEG e Webp, na Figura 10, Figura 11 e Figura 12. Nesse caso, pode-se observar que o padrão que possui melhor desempenho para as necessidades de transmissão multimídia utilizando a faixa de ondas curtas é o Webp, já que obteve um arquivo de menor tamanho com qualidade satisfatória para transmissão e recepção. Por exemplo, a imagem I01.webp, para um fator de compressão de $75 \%$, obteve um arquivo de tamanho de $8 \mathrm{kB}$ e um PSNR de 38,66 dB enquanto a imagem I01.jpg, para o mesmo fator de compressão, apresentou um arquivo de tamanho de $13 \mathrm{kB}$ e um PSNR de 62,15 dB.

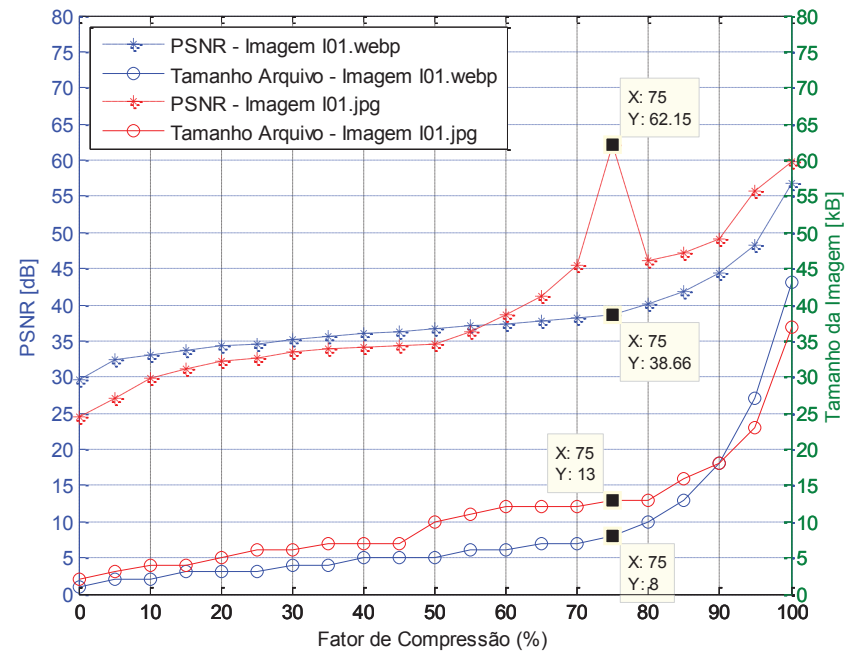

Fig. 10. Análise da imagem I01 em função do PSNR, do Tamanho do Arquivo e do Fator de Compressão.

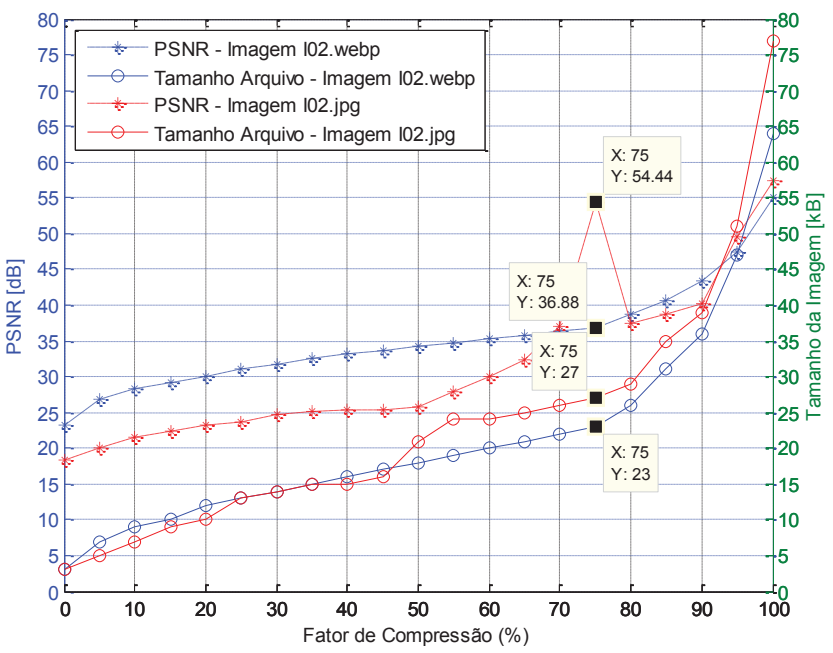

Fig. 11. Análise da imagem I02 em função do PSNR, do Tamanho do Arquivo e do Fator de Compressão.

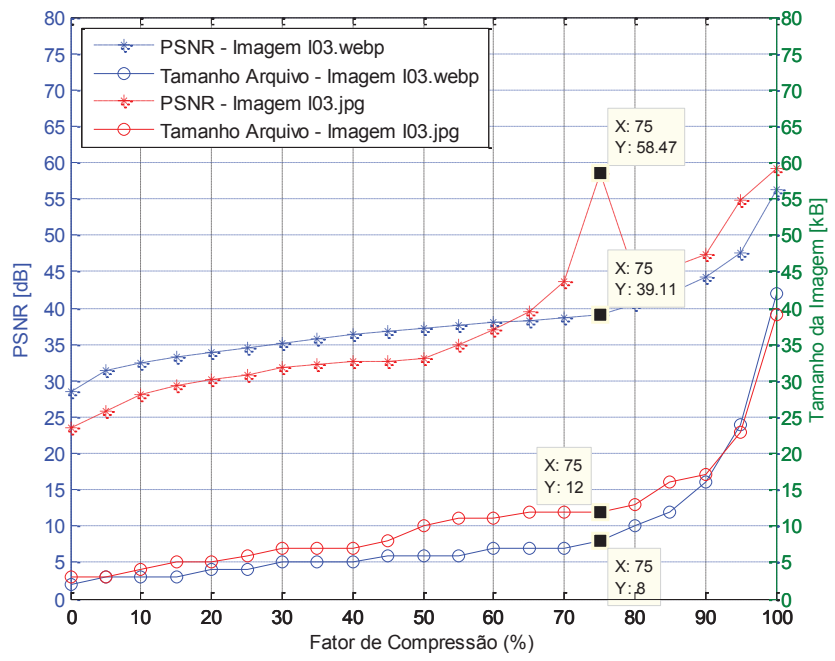

Fig. 12. Análise da imagem I03 em função do PSNR, do Tamanho do Arquivo e do Fator de Compressão.

\section{B. Arquivo em Powerpoint}

O programa PowerPoint da Microsoft é uma importante ferramenta na construção de documentos destinados às apresentações gráficas de instrução e aprendizado de um determinado tema. Assim, o seu estudo é necessário quando se decide utilizar essa ferramenta como meio de produção de conteúdo a ser transmitido por um dispositivo móvel, a exemplo do rádio digital. Portanto, foi definido um procedimento para viabilizar este estudo, com a montagem de arquivos em PowerPoint objetivando encontrar aquele que ocupasse o menor espaço em disco e mantivesse uma qualidade aceitável para a transmissão, por meio de um dispositivo com resolução de tela no formato de $320 \times 240$.

Assim foi criado um arquivo em PowerPoint sem qualquer informação inserida para se comparar com os arquivos preenchidos com as imagens. A esse arquivo vazio foi dado o nome de "PP_vazio_pptx", com tamanho de 32 kB. Posteriormente foram criados arquivos com cada uma das imagens descritas na Tabela IV. O resultado dos arquivos em 
PowerPoint com cada imagem pode ser observado na Figura 13.

TABELA IV

RESOLUĊ̃O E TAMANHO DE IMAGENS UTILIZADAS NO POWERPOINT

\begin{tabular}{cccc}
\hline \hline Imagem & Formato & Resolução & $\begin{array}{c}\text { Tamanho } \\
\text { em disco } \\
\text { em kB }\end{array}$ \\
\hline \multirow{4}{*}{ I01 } & Bitmap & & 226 \\
& GIF & $320 \times 240$ & 58 \\
& JPEG & & 13 \\
& PNG & & 132 \\
& Webp & & 8 \\
\hline \multirow{4}{*}{ I02 } & Bitmap & & 226 \\
& GIF & $320 \times 240$ & 72 \\
& JPEG & & 27 \\
& PNG & & 178 \\
& Webp & & 23 \\
\hline \multirow{4}{*}{ I03 } & Bitmap & & 226 \\
& GIF & $320 \times 240$ & 50 \\
& JPEG & 12 \\
& PNG & & 128 \\
\hline \hline
\end{tabular}

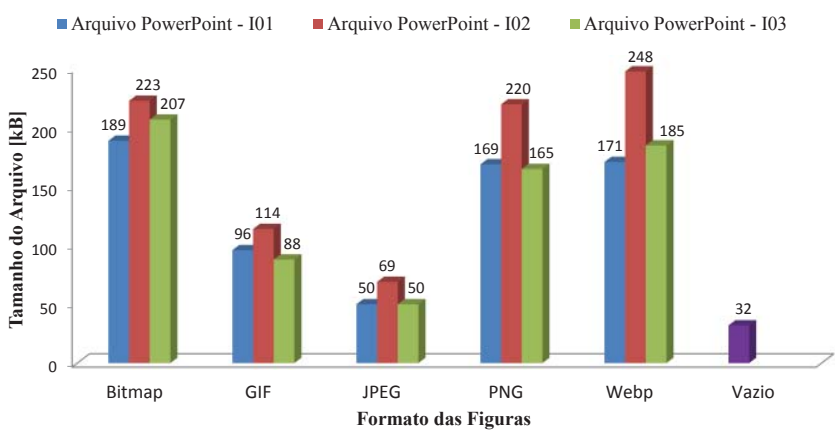

Fig. 13. Arquivos PowerPoint com figuras com resolução $320 \times 240$.

Da Figura 13 pode-se observar que os arquivos que cumpriram com o objetivo de menor ocupação de espaço em disco foram aqueles nos quais se inseriu imagens no formato JPEG.

Uma segunda análise foi realizada exportando os slides criados com imagens JPEG no PowerPoint (.pptx) para os formatos de figura JPEG, PNG, GIF e Webp. Com a exportação desses arquivos o objetivo era observar quais arquivos exportados apresentavam menor ocupação de espaço em disco. Os resultados podem ser analisados na Figura 14.

$$
\text { -I01 } \because \mathrm{I} 02-\mathrm{I} 03 \text {-vazio }
$$

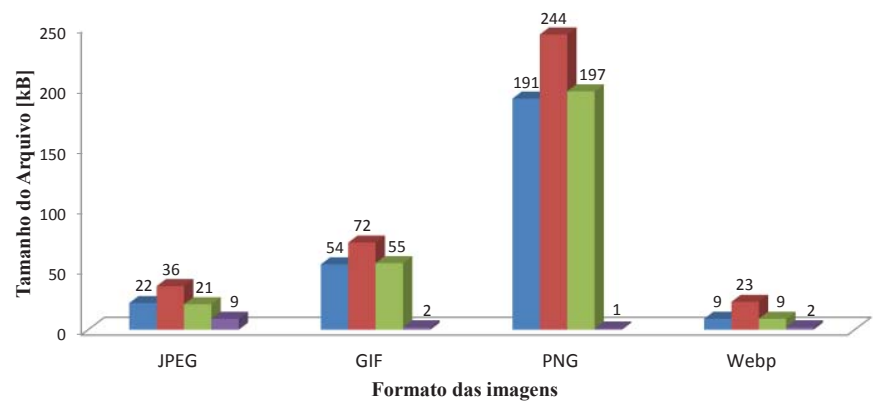

Fig. 14. Arquivos PowerPoint com figuras JPEG exportadas em imagens de resolução $960 \times 720$.

Observa-se que os arquivos PowerPoint exportados em formatos de imagens na resolução padrão do programa de 960 × 720 que cumprem com o objetivo procurado são os Webp, que foram criados a partir das imagens JPEG por meio do programa cwebp [10].

No entanto, todos os arquivos PowerPoint foram criados com as imagens ocupando apenas uma parte do slide, daí surge a necessidade de verificar qual seria o comportamento dos arquivos se as imagens inseridas ocupassem toda a área útil do slide. Para isso, os arquivos foram inseridos no slide e redimensionados para que ocupassem toda a área do slide. As imagens foram inseridas na resolução $512 \times 384$ no formato Bitmap e na resolução $320 \times 240$ no formato JPEG, conforme Figura 15.

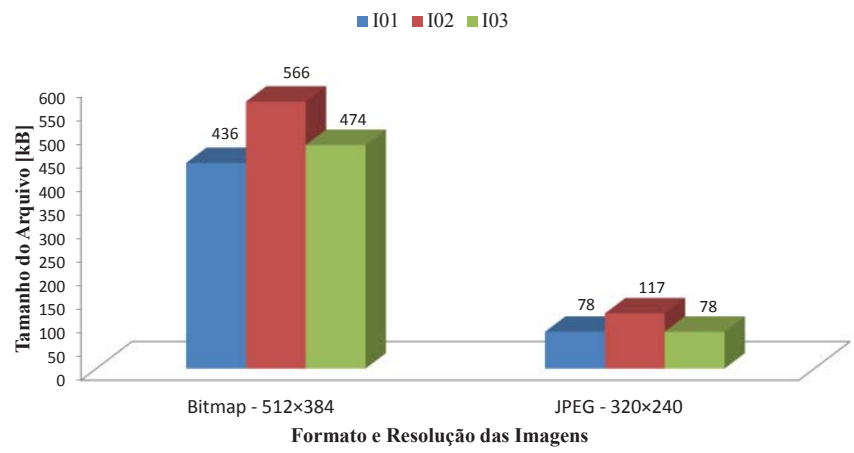

Fig. 15. Arquivos PowerPoint com figuras ocupando área total do Slide.

Após a construção dos arquivos em PowerPoint, eles foram exportados com formato de imagens JPEG, GIF, PNG, tendo sua resolução de exportação final alterada do padrão $960 \times$ 720 para a resolução $320 \times 240$. O formato Webp foi obtido pela conversão do arquivo exportado em formato JPEG, por meio do programa cwebp. O resultado está ilustrado na Figura 16.

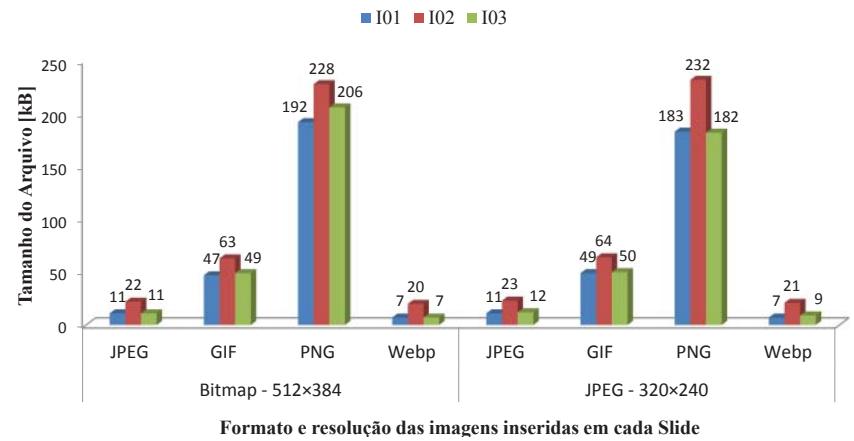

Fig. 16. Arquivos PowerPoint exportados como imagem de resolução $320 \times 240$.

Pode-se observar que, mesmo as figuras inseridas no formato Bitmap e resolução $512 \times 384$, que ocupam maior espaço em disco, quando inseridas em um arquivo PowerPoint e exportadas como imagens, ocupam menor ou igual espaço em disco que os arquivos aos quais foram inseridas imagens no formato JPEG e resolução $320 \times 240$. Com exceção das figuras 01 e 03 no formato PNG, o que representa uma amostra pequena desta relação.

Assim, conclui-se que, para chegar ao formato de arquivo do PowerPoint com resolução de $320 \times 240$ de melhor 
desempenho para transmissão e características aceitáveis de qualidade, é necessária a inserção de imagens no formato JPEG, conforme Figura 15. Para estas condições, quando se trata de verificar a melhor imagem proveniente da exportação de um arquivo com origem no PowerPoint, observa-se que a resolução desta imagem inserida no Slide tem pouca influência no resultado final da exportação e conversão, desde que o arquivo final tenha o formato Webp, conforme Figura 16.

Para chegar aos resultados de menor resolução mostrados na Figura 16, foi necessário alterar a forma padrão de como o PowerPoint exporta os arquivos de imagens, essa alteração é feita na chave do registro do programa [11].

\section{Arquivo Fontes}

Seguindo a metodologia de se encontrar os arquivos em PowerPoint que ocupem o menor espaço físico em disco foi realizada a criação de slides apenas com caracteres alfanuméricos, seguindo a variação dos arquivos de fonte do Windows, nos tamanhos de 12, 18, 24, 36, 48, 60 e 72 de três fontes, são elas: Arial, Times New Roman e Broadway.

Os caracteres alfanuméricos inseridos em todos os arquivos foram: "abcdefghijklmnopqrstuvwxyz" e "1234567890". Primeiramente foram criados arquivos PowerPoint (.pptx) e observado seus tamanhos em disco, conforme ilustra a Figura 17.

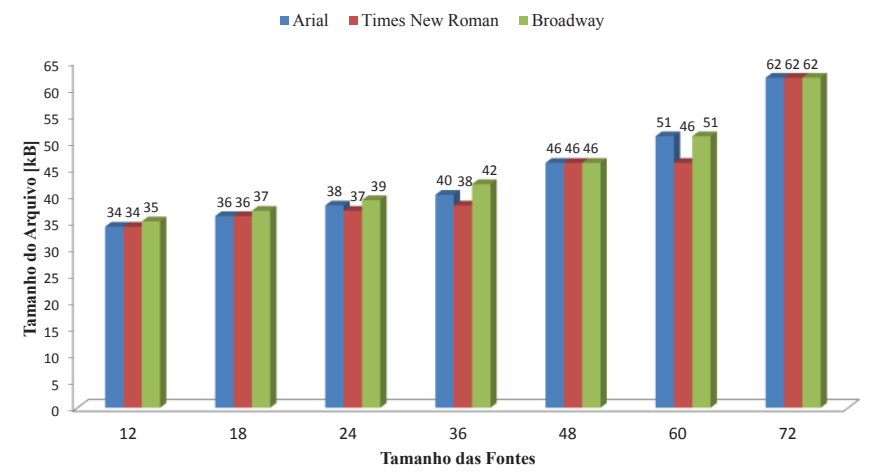

Fig. 17. Arquivos PowerPoint, Tipos e Tamanho de Fonte.

Após a criação dos arquivos em PowerPoint, os slides foram exportados no formato de figuras em JPEG, PNG, GIF e resolução $320 \times 240$. O formato JPEG foi convertido em Webp, com Fator de Compressão padrão de 75\% utilizando o programa cwebp. O resultado é ilustrado na Figura 18, onde pode ser verificada a relação entre o tamanho do arquivo e a formatação das fontes em tamanho e tipo.

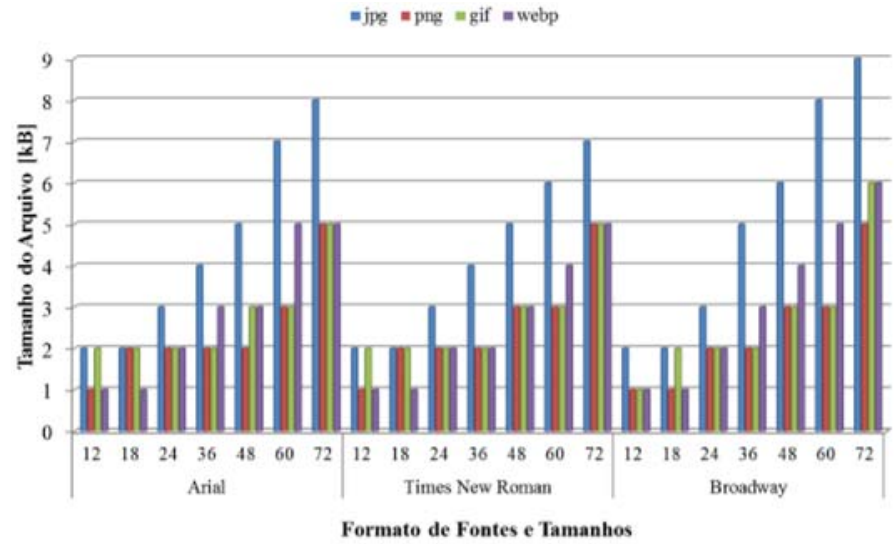

Fig. 18. Arquivos PowerPoint convertidos em imagens $320 \times 240$.

Nessa fase, conclui-se que os arquivos em PowerPoint, com apenas inserção de caracteres alfanuméricos, possuem uma alteração pequena quando se varia o tipo da fonte, sendo que a maior diferença ocorre quando se varia o tamanho da fonte. Essa relação também é verdadeira ao transformar estes arquivos em imagens.

Atualmente, o conteúdo em arquivos PowerPoint possui uma representação significante dentro do grupo de conteúdo multimídia direcionado a aprendizagem educacional. A sua transformação em imagem estática significa a perda de alguns recursos de interatividade deste programa, por exemplo, a animação. Por outro lado, representa grande ganho no que diz respeito ao tamanho final do arquivo, o que se mostra importante para a transmissão deste tipo de informação por meio do sistema apresentado.

\section{Plataforma PARA TeStes}

Para transmissão e recepção dos conteúdos analisados na seção III, foi implementada uma plataforma composta de três estágios, "Servidor de Conteúdo", "Sistema de Transmissão" e "Recepção", conforme ilustra a Figura19 [12].

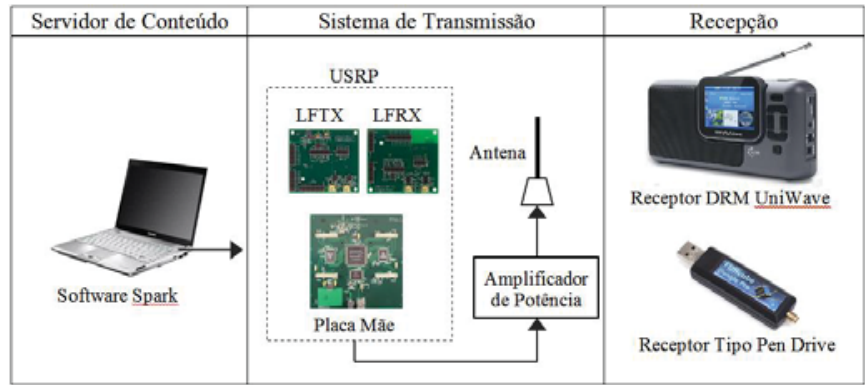

Fig. 19. Plataforma utilizada nos testes.

\section{A. Servidor de Conteúdo}

O Software Spark, além de Servidor de Conteúdo é um modulador DRM30, DRM+, FM e AM, que utiliza o conceito de Rádio Definido por Software - SDR (Software Defined Radio) para operar nas seguintes faixas de frequências: MF, HF e VHF. O SDR é um dispositivo de comunicação sem fio que possui parte de suas funções implementadas por software 
em computador, em vez de usar componentes fixos de hardware [13]. Assim, é possível, utilizando o software, inserir vários tipos de serviços agregados ao áudio da emissora, mas sempre considerando as limitações da capacidade de transmissão de um sistema de comunicação digital [14]. A Figura 20 ilustra as telas de abertura do Spark e a configuração do Servidor de Conteúdo licenciado para os testes em OC no Brasil.

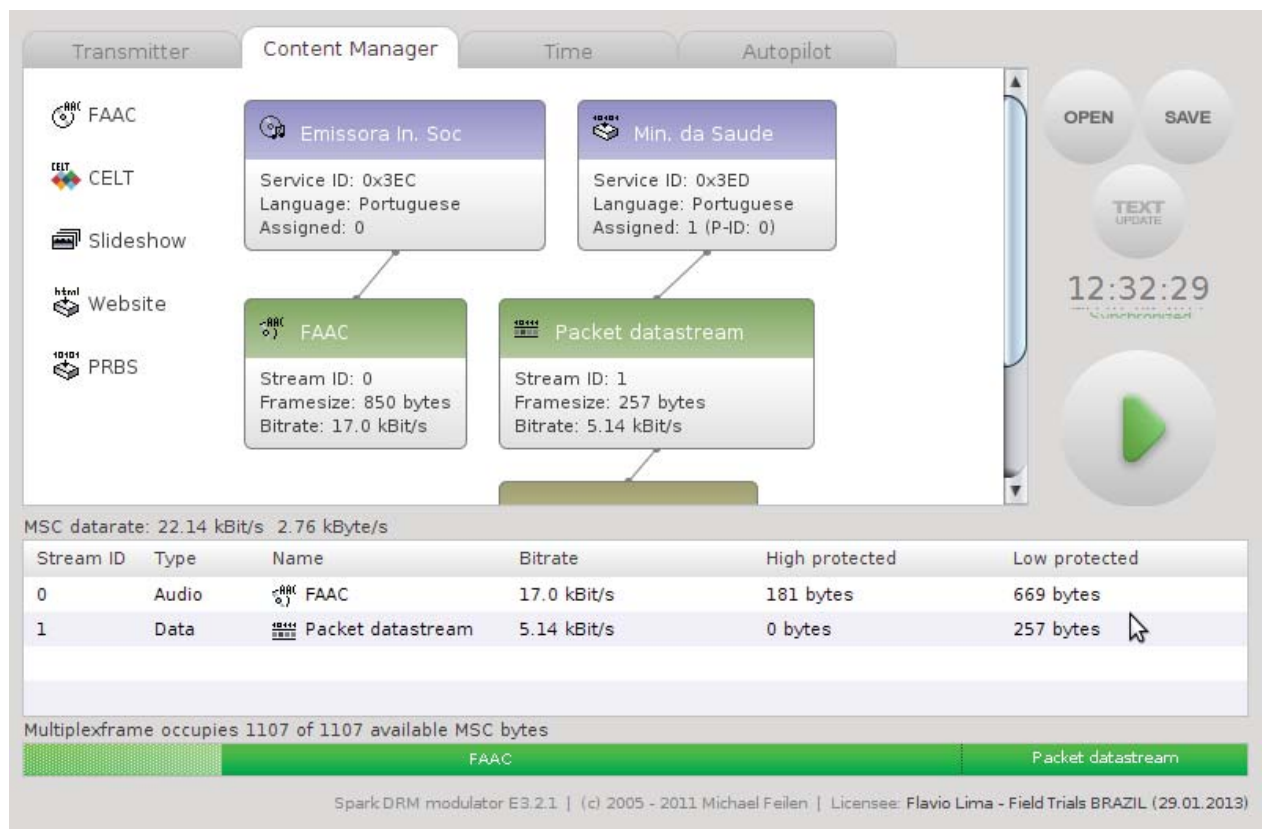

Fig. 20. Servidor de Conteúdo Spark.

\section{B. Sistema de Transmissão}

O Sistema de Transmissão tem como componente principal uma plataforma aberta de baixo custo, chamada de USRP (Universal Software Radio Peripheral) [15], responsável pela segunda parte do processamento exigido em um sistema SDR, ou seja, transformar o processamento feito pelo software em Rádio Frequência - RF. Portanto, a USRP é formada por dois componentes principais: a placa mãe com conexão USB para comunicação com o computador, responsável pelas funções programáveis mais complexas, implementadas em uma Altera Cyclone FPGA (Field Programmable Gate Array), e duas placas filhas ou daughterboards, LFTX e LFRX, que contêm o módulo de radiofrequência, responsável pela sintonia da frequência central utilizada pelo dispositivo na transmissão e/ou recepção [16].

Devido às restrições impostas em cada país para a radiação de sinais não licenciados, cujo limite no Brasil é de $100 \mathrm{~mW}$ [17], a placa filha LFTX foi ajustada para disponibilizar em sua saída uma potência de apenas $2 \mathrm{~mW}$, ou seja, de aproximadamente $3 \mathrm{dBm}$. Assim, de maneira a obter um nível de sinal adequado à sensibilidade do receptor localizado a uma determinada distância do transmissor, foi colocado na saída da USRP um amplificador de potência, o Ultra Linear PostAmp, de $30 \mathrm{~dB}$ de ganho (de $-10 \mathrm{dBm}$ a $+20 \mathrm{dBm}$ ), operando na faixa de frequência de 1 a $150 \mathrm{MHz}$ e com potência máxima de saída de $100 \mathrm{~mW}$ [18]. Para irradiar o sinal, uma antena modelo CB-20 com ganho de $2,15 \mathrm{~dB}$ e VSWR $\leq 1,5$, operando em $27 \mathrm{MHz}$, foi acoplada ao amplificador de potência.

\section{Sistemas de Recepção}

Para recepção do sinal irradiado, foi utilizado um receptor comercial UniWave, modelo Di-Wave 100, que opera nas faixas de ondas médias, tropicais e curtas nos modos analógico e digital, e na faixa de FM apenas no modo analógico. O UniWave, além de prover o áudio como qualquer receptor convencional, foi desenvolvido para operar com o sistema DRM, sendo portanto um receptor multimídia capaz de decodificar textos, imagens estáticas e em movimento e vídeos. O receptor Di-Wave 100 permite a recepção de inúmeras imagens e conteúdos de dados no modo carrossel, o que significa que as imagens ficam à disposição do usuário durante todo o tempo em que o aparelho permanecer ligado, podendo ser salvas na memória interna do receptor ou em cartões de memória externos ao aparelho.

Concomitantemente foi implementado um receptor alternativo via computador utilizando um receptor de sinal RF FUNcube Dongle Pro+ Serial 13660 e o software Dream, que é gratuito, com mesmas funcionalidades do receptor UniWave além do recebimento de páginas da internet (arquivos em HTML) e monitoramento de parâmetros do sinal DRM tais como intensidade de campo elétrico, formato do espectro, constelações dos canais MSC, FAC e SDC, Densidade Espectral do Áudio, etc, conforme ilustra a Figura 20 [19]. 


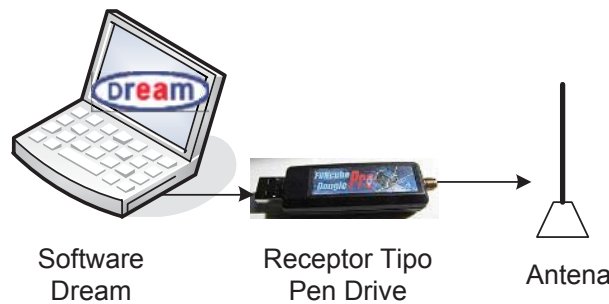

Fig. 21. Receptor alternativo implementado via computador.

\section{Testes e Resultados}

$\mathrm{O}$ critério adotado para se determinar o formato ideal da imagem a ser transmitida consistiu basicamente na economia de banda da transmissão, sendo adotado o formato que apresentou melhor relação entre a ocupação de espaço em disco e qualidade.

\section{A. Testes com Imagens e Áudio}

Para o formato de imagens, verificou-se que o padrão Webp para a transmissão era o mais adequado. No entanto, os codificadores disponibilizados na plataforma de teste não contemplavam o decodificador Webp. Assim, para a transmissão foi adotado o padrão de imagem JPG, qualificado em segundo lugar por meio dos mesmos critérios. A Tabela V apresenta a configuração utilizada no servidor de conteúdo.

TABELA V

CONFIGURAÇÃO NO SERVIDOR DE CONTEÚDO PARA TRANSMISSÃO DE IMAGENS JPEG.

\begin{tabular}{cccc}
\hline \hline Configuração dos Dados & \multicolumn{2}{c}{ Configuração do Canal MSC } \\
\hline \hline Conteúdo & $\begin{array}{c}\text { Tamanho em } \\
\text { kB (kilo Byte) }\end{array}$ & Tipo & $\begin{array}{c}\text { Taxa de } \\
\text { Transmissão em } \\
\text { kbps }\end{array}$ \\
\hline I01.jpg & 12,51 & $\begin{array}{c}\text { Áudio } \\
\text { (AAC/FAAC) }\end{array}$ & 16 \\
\hline I02.jpg & 27,45 & $\begin{array}{c}\text { Pacote de } \\
\text { Dados } \\
\text { (Datastream) }\end{array}$ & 5,54 \\
\hline I03.jpg & 12,28 & ------ & ------ \\
\hline \hline
\end{tabular}

O tempo de recepção do pacote de áudio, foi praticamente instantâneo, sendo considerado apenas o tempo de processamento do sinal digital no decodificador. Já a recepção das imagens após o primeiro minuto de transmissão teve uma variação de 20 segundos, sendo a primeira imagem recebida pelo receptor UniWave após 1 minuto $(1 \mathrm{~m} 00 \mathrm{~s})$ do início da transmissão, a segunda imagem após 1 minuto e 20 segundos ( $1 \mathrm{~m} 20 \mathrm{~s})$ e a terceira após 1 minuto e 40 segundos (1m40s). A Figura 22 ilustra a tela do receptor UniWave com as imagens recebidas.

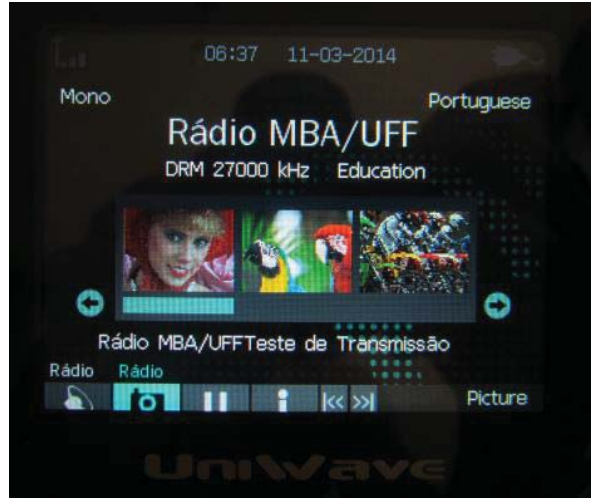

Fig. 22. Tela do receptor UniWave.

\section{B. Testes com PowerPoint e Áudio}

Para o formato de arquivos PowerPoint, convertidos em imagens, novamente o padrão melhor qualificado foi o Webp, mas pelas mesmas razões encontradas nos testes de transmissão das imagens, foi adotado o padrão JPEG para a transmissão, mantendo a configuração apresentada na Tabela $\mathrm{V}$.

Após a transmissão do pacote de informações, o tempo de recepção das imagens foi de 50 segundos (50s) para a recepção da primeira imagem, 1 minuto e 10 segundos (1m10s) para a segunda imagem e 1 minuto e 30 segundos (1m30s) para a terceira.

Para o formato de arquivos PowerPoint, convertido em imagens, com as fontes em caracteres alfanuméricos, o formato de arquivo melhor qualificado foi o PNG. Após a transmissão do pacote de informações com o tipo de fonte de Times New Roman e tamanho 36, o tempo de recepção das imagens foi de 04 segundos $(04 \mathrm{~s})$ para a recepção da primeira imagem, 08 segundos (08s) para a segunda imagem e 12 segundos (12s) para a terceira.

\section{Testes com Página HTML e Áudio}

Por último, um pacote de dados (MOT Website) foi utilizado para transmissão de uma página HTML, contendo texto e imagem, conforme ilustra a Figura 23. Adicionalmente, foi incluído o áudio utilizado em todos os outros testes. A Tabela VI detalha a configuração utilizada. $\mathrm{Na}$ recepção, foi utilizado um receptor alternativo de maneira a verificar a recepção da página HTML, bem como a sua funcionalidade.

TABELA VI

CONFIGURAÇ̃̃O NO SERVIDOR DE CONTEÚDO PARA TRANSMISSÃO DE IMAGENS E PÁGINAS HTML.

\begin{tabular}{cccc}
\hline \hline \multicolumn{3}{c}{ IMAGENS E PAGINAS HTML. } \\
\hline \hline Configuração dos Dados & \multicolumn{2}{c}{ Configuração do Canal MSC } \\
\hline I01.jpg & $\begin{array}{c}\text { Tamanho em } \\
\mathrm{kB}\end{array}$ & Tipo & $\begin{array}{c}\text { Taxa de } \\
\text { Transmissão em } \\
\text { kbps }\end{array}$ \\
\hline I02.jpg & 27,51 & $\begin{array}{c}\text { Áudio } \\
\text { (AAC/FAAC) }\end{array}$ & 14 \\
\hline
\end{tabular}




\begin{tabular}{cccc}
\hline & \multicolumn{3}{c}{$\begin{array}{c}\text { Imagens } \\
\text { (Datastream) }\end{array}$} \\
\hline I03.jpg & 12,28 & $\begin{array}{c}\text { Pacote de } \\
\text { Dados para } \\
\text { Páginas HTML } \\
\text { (Datastream) }\end{array}$ & 2,56 \\
\hline Página & 13 & ----- & ------ \\
HTML & 13 \\
\hline \hline
\end{tabular}

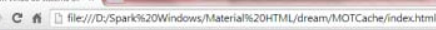

Bem vindo!

Sistema de Rádio Digital.

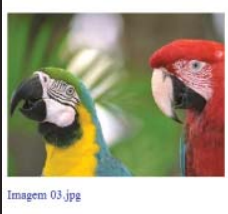

Fig. 23. Página HTML transmitida no DRM30

Os pacotes transmitidos tiveram como resultado de recepção no software descrito, os seguintes tempos de recepção: Áudio sete segundos (07s), página HTML index cinquenta segundos (50s), Imagem 011 minuto e vinte e seis segundos (1m26s), Imagem 021 minuto e cinquenta e dois segundos (1m52s) e, Imagem 032 minuto e 28 segundos $(2 \mathrm{~m} 28 \mathrm{~s})$.

A diferença entre os tempos de recepção e decodificação do áudio do primeiro teste utilizando o receptor UniWave e o segundo teste utilizando o receptor via software DREAM pode se atribuída ao tempo de processamento requerido por cada setup de recepção. Sendo assim, essa variação nos tempos de recepção era esperada devido ao processamento digital e à capacidade de processamento distinta de cada sistema de recepção.

\section{CONSIDERAÇÕES FINAIS}

Este artigo apresentou os resultados da avaliação de algumas ferramentas utilizadas nos serviços multimídia, identificando o uso mais adequado para o desenvolvimento de conteúdos a serem utilizados no serviço de radiodifusão digital na faixa de ondas curtas, levando em consideração as melhores características técnicas para a produção do conteúdo a ser transmitido em tecnologia de banda estreita.

Dentre os formatos de imagens apresentadas e testadas, identificou-se que o padrão Webp possui o comportamento mais adequado dentre os avaliados para ser utilizado na transmissão de tecnologia de banda estreita. Arquivos com menores ocupações físicas em Byte, e com degradação não perceptível ao usuário em relação à imagem original, farão melhor uso da banda do sistema DRM30 e, consequentemente reduzirão o tempo de transmissão. No entanto, o DRM30 não contempla o decodificador Webp no receptor UniWave utilizado nos testes. Nesse caso, dentre os analisados, o padrão JPEG deve ser utilizado. Por outro lado, no tratamento de página HTML utilizando o Navegador Google Chrome para visualização do conteúdo recebido, o uso de imagens Webp é recomendável.
Adicionalmente, verificou-se que, no uso de arquivos originalmente gerados em PowerPoint, os slides devem ser exportados para o formato JPEG. Caso o DRM30 venha a contemplar o decodificador Webp, recomenda-se que o arquivo PowerPoint no formato JPEG passe por mais uma etapa de conversão, ou seja, de JPEG para Webp, obtendo assim o melhor uso da largura de banda disponível sem perda de qualidade perceptível ao usuário.

Diante dos resultados apresentados nesse artigo, o serviço em Ondas Curtas ressurge como uma nova alternativa para a inclusão social, principalmente em áreas remotas, possibilitando entreter e informar cidadãos, além de possibilitar a educação a distância, em localidades onde outros meios de comunicações não estão presentes ou acessíveis a uma parcela da população.

Finalmente, cabe salientar que outras análises deverão ser desenvolvidas, de maneira a identificar demais ferramentas não contempladas nesse trabalho, por exemplo, transmissão de vídeo e de aplicativos. Adicionalmente, pesquisas para elaboração e/ou adaptação de metodologias atualmente utilizadas por outros meios de comunicação devem ser testadas, sempre considerando as limitações da tecnologia do serviço em OC em relação à largura de banda e à transmissão simplex. Assim, surgem novos desafios para os profissionais da área de educação, informática, engenharia, entre outras.

\section{REFERÊNCIAS}

[1] ETSI TS 101 980: "Digital Radio Mondiale (DRM); System Specification", v1.1.1, 2001.

[2] Rec. ITU-R BS.1514-1: "Systems for digital sound broadcasting in the broadcasting bands below $30 \mathrm{MHz}$ ", 2002.

[3] ETSI ES 201980 V4.1.1. "Digital Radio Mondiale (DRM), System Specification", 2014-01.

[4] M. Dietz, L. Liljeryd, K. Kjorling and O. Kunz. "Spectral Band Replication, a novel approach in audio coding," in Proc. Audio Engineering Society, Munich, Germany, May 2002. Available: http://129.97.134.72:8888/000225.PDF.

[5] Dietz, M. e Meltzer, S, "CT-aacPlus - A state-of-the-art audio coding system”, EBU Technical review N²91, 2002.

[6] Apresentações do Conselho Consultivo do Rádio Digital, "Mapeamento dos serviços e dos aplicativos disponíveis no Digital Radio Mondiale". Available: http://www.mc.gov.br/radiodifusao/acoes-e-programas/radiodigital/251-temas/radio-digital/26495-apresentacoes-da-reuniao-doconselho-consultivo-do-radio-digital-no-dia-28-de-fevereiro.

[7] N.Ponomarenko, M.Carli, V.Lukin, K. Egiazarian, J. Astola, F. Battisti, "Tampere Image Database 2008 TID2008", version 1.0. Available: http://ponomarenko.info/tid2008.htm.

[8] Z. Wang, A.C. Bovik, H.R. Sheikh and E.P. Simoncelli, "Image quality assessment: from error visibility to structural similarity,"IEEE Transactions on Image Processing, vol.13, no.4, pp. 600- 612, April 2004.

[9] Z. Wang, E. P. Simoncelli, and Alan B. Bovik, "Multi-Scale Structural Similarity for Image Quality Assesssment,"Proceedings of the $37^{\text {th }}$ Asilomar Conference on Signals, Systems and Computers, Pacific Grove, CA, Nov. 9-12, 2003.

[10] Available: https://developers.google.com/speed/webp/download?hl=pt-BRZ.

[11] Available: https://support.microsoft.com/pt-br/kb/8277451111111.

[12] A.A Menezes, F. F. Lima, J. G. Silva, R. S. Motta, P. J. G. Mata; R. S. Almeida, R. F. S. Araújo, "Desenvolvimento de uma Plataforma para Estudos da Inclusão Social em Áreas Remotas por Meio da 
Radiodifusão Digital na Faixa de Ondas Curtas", Anais do ConicSemesp, Volume1, 2013, ISSN 2357-8904.

[13] J. Mitola, "The software radio architecture. Communications", Magazine, IEEE, p. 26-38, 1995.

[14] Leon, W. C, "Digital \& Analog Communication Systems", 6 Edition, January 2001.

[15] Ettus, M. Universal Software Radio Peripheral, 2009. Available: http://www.ettus.com.

[16] P. Balister. \& J. Reed, "USRP Hardware and Software Description", Virginia Tech Edition, June 2006.

[17] Anatel, Regulamentos. Available: http://www.anatel.gov.br/Portal/exibirPortalInternet.do.

[18] PostAmp, "Ultra Linear PostAmp," Edition 08/2009. Available: http://www.nti-online.de/ePostAmp1-150.htm.

[19] Dream, "DRM Receiver". Edition 08/2009. Available: $\mathrm{http}: / /$ sourceforge.net/projects/drm/.

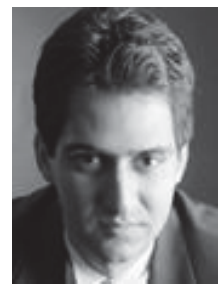

Hebert Santos recebeu o título de Especialista em TV Digital, Radiodifusão e Novas Mídias de Comunicação Eletrônica pela Universidade Federal Fluminense, Niterói, Rio de Janeiro, em 2014 e a Graduação em Engenharia Elétrica pela Pontifícia Universidade Católica de Goiás, Goiânia, Goiás, em 2006

Em 2006 ingressou na carreira pública do Poder Executivo Federal no cargo de Engenheiro Eletricista, atuando em funções de Direção e Assessoramento Superior, ao longo do tempo integrou Grupos de Estudos e Normas Técnicas de Radiodifusão, Grupo Permanente de Estudos de Radiointerferência, Comitê de Tecnologia da Informação e do Grupo de Execução e Acompanhamento dos testes dos padrões de Rádio Digital.

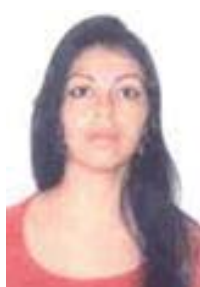

Amanda Abreu Menezes Graduada em Sistema de Telecomunicações pela Faculdade Facnet em 2006, e em Pedagogia pela mesma Faculdade em 2014. Recebeu o título de Especialista em Redes de Telecomunicações pela Faculdade Anhanguera unidade FACNET, Brasília, Brasil, em 2009. Atualmente é professora e coordenadora do Curso de Pedagogia na Faculdade Anhanguera e Mestranda na Nihon Gakko University (Ciudad del Lest, Paraguai). Sua área de pesquisa é voltada para novas tecnologias de radiodifusão digital aplicada à educação à distância.
Gilvandson Costa Cavalcante Graduado em Engenharia

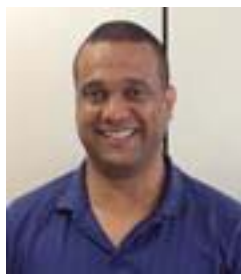
Eletrônica pela Universidade de Brasília (UnB) em 2014. Atualmente é Mestrando na mesma universidade, e servidor público federal do Ministério das Comunicações.

Sidnei Baumann recebeu o título de Mestre em Ciências da

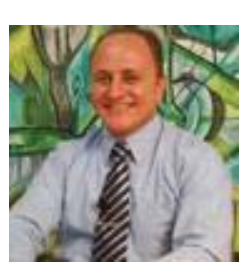
Educação pela Universidade Tecnológica Intercontinental Ciudad del Lest, Paraguai, em 2010, e o título de Doutor da Universidade Nihon Gakko, Ciudad del Lest, Paraguai, em 2014. Atualmente é professor da Universidade Nihon Gakko e desenvolve pesquisa sobre novas plataformas tecnológicas voltadas à educação à distância.

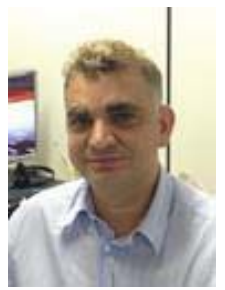

Flávio Ferreira Lima recebeu o título de Mestre em Engenharia Elétrica pela Universidade de Brasília, Brasil, em 2002 e o título de Doutor da mesma universidade em 2008 na Área de Radiodifusão Digital. Atualmente é professor da Faculdade Anhanguera em Brasília, Brasil, e colaborador das Universidades Nihon Gakko, Ciudad del Lest, Paraguai e Universidade de Brasília, Brasília, Brasil, e engenheiro do Ministério das Comunicações, Brasília, Brasil. Sua área de pesquisa é voltada para novas tecnologias de radiodifusão, incluindo DRM (Digital Radio Mondiale), HD Radio System e ISDB-T (Integrated Service Digital Broadcasting Terrestrial).

Cite this article:

Santos,H., A. Menezes, A., C. Cavalcante,G., Baumann, S., F. Lima, F.; 2015. Análise de Conteúdo Multimídia para Radiodifusão Digital Operando na Faixa de Ondas Curtas. SET EXPO PROCEEDINGS. ISSN Print: 2447-0481.ISSN Online: 2447-049X. v.1.doi: 10.18580/setep.2015.1.5 Web-link: http:// dx.doi.org/10.18580/setep.2015.1.5 